\title{
Imagens em materiais didáticos impressos \\ para o ensino de Física num curso de Licenciatura \\ semipresencial
}

Sheila Cristina Ribeiro Rego

Guaracira Gouvêa

\begin{abstract}
Resumo
O objetivo do presente artigo é expor o resultado da análise das imagens presentes em material didático impresso utilizado na disciplina Introdução às Ciências Físicas 1 (ICF 1) da modalidade semipresencial do curso de Licenciatura em Física da Universidade Federal do Rio de Janeiro (UFRJ). Para isso, examinamos as formas de produção das imagens, os elementos que as compõem e seu nível de iconicidade. Apresentamos algumas características das "tecnologias" de produção e recepção de imagens levantadas por Dubois (1999). A análise do material confirma o uso que se faz no ensino de Física de imagens com algo grau de abstração para o entendimento de conceitos científicos. Não encontramos imagens provenientes de simulações computacionais, ou de programas de televisão, vídeo e cinema. Houve uma frequência baixa de fotografias, sendo a maioria das imagens originadas de desenhos. Os elementos que compõem as imagens analisadas, geralmente, apresentam-se acompanhados de esquemas da Física.
\end{abstract}

Palavras-chave: imagem fixa, Física, material didático.

\begin{tabular}{l} 
Abstract \\
Physics Teaching in a semi-distance Teaching Degree course: printed \\
images on educational materials \\
The aim of this paper is to present the results of the analysis of \\
images on printed educational materials used in the course Introduction to \\
Physical Science 1 ( 1 ICF) of the semi-distance modality Teaching Degree in \\
Physics, by the Federal University of Rio de Janeiro (UFRJ). To this end, we \\
examined ways of producing images, the elements within them and their \\
level of iconicity. This paper presents some characteristics of the \\
\hline
\end{tabular}


"technology" used for production and reception of images collected by Dubois (1999). The analysis of this material confirms the use of images with a high level of abstraction to support scientific concepts during Physics lessons. We could not find pictures from computer simulations, or television programs, video and film. There was a low frequency of photographs, most of the images originated from drawings. The elements that composed the images analyzed were generally presented as schemes.

Keywords: images, Physics, educational material

\section{Introdução}

A linguagem vem sendo amplamente estudada em diversas áreas, tais como: Filosofia, Psicologia, Linguística, Comunicação, Cultura, Educação etc. Mais recentemente, pesquisas têm se preocupado com o uso e a leitura da linguagem imagética, seja abordando a imagem como objeto de estudo ou utilizando-a na tentativa de compreender outras questões, dentre elas a cultura (Macedo, 2004), a produção de textos narrativos (Teixeira; Compiani; Newerla, 2006) e o desenvolvimento de estratégias pedagógicas (Costa et al, 2006, 2007). Em levantamento realizado em 77 periódicos classificados como da área da Educação pela Coordenação de Aperfeiçoamento de Pessoal de Nível Superior (Capes), encontramos 156 artigos que fazem referência em seus títulos à imagem visual fixa, publicados no período de 1998 a 2007, dos quais, aproximadamente, 70\% foram publicados a partir de 2003.

Não é novidade a utilização da imagem no ambiente escolar, e mais precisamente em materiais didáticos. Data de 1685 o primeiro livro didático em que as imagens possuem um papel fundamental na transmissão do conhecimento, o Orbissensualiumpictus(Mundo sensível ilustrado) de Comenius (Comenius, 1685 apud Chalmel, 2004). Nele, a imagem era utilizada para substituir objetos que deveriam ser manipulados para um melhor aprendizado, mas que, por motivos diversos, não se encontravam disponíveis ao professor e aos alunos. A imagem era utilizada para ilustrar o texto.

Com o passar do tempo, houve uma inversão no papel do texto e da imagem (Barthes, 1990): o texto passou a direcionar a interpretação da imagem, conduzindo a sentidos preferenciais de leitura.

Hoje, admite-se que, ambos, texto e imagem, exercem seu papel na leitura da mensagem que se quer transmitir, seja no entendimento do significado literal da mensagem e/ou na compreensão de sentidos segundos para os quais o autor pretende dirigir o leitor. 
"A tradicional complementaridade entre palavra e imagem é hoje percebida com base na distinção das respectivas qualidades e deficiências de um e de outro meio de expressão. Às vezes a imagem é designada para 'ilustrar' a palavra, isto é, iluminar algo que se presume 'obscuro' no sentido imanente da palavra. Em outros casos a palavra determina o sentido da imagem contra o poder sedutor da representação imediata." (Schollhammer) ${ }^{1}$

As imagens presentes em materiais didáticos para o ensino de Ciências apresentam particularidades relacionadas à finalidade de estabelecer conceitos científicos que, geralmente, diferem dos que os estudantes adquirem de sua experiência cotidiana com os fenômenos e objetos ao redor (Bachelard, 2005). Para isso, faz-se necessário trabalhar com imagens que possuem alto grau de abstração e, consequentemente, pouca semelhança com a realidade conhecida por eles, mas que ajudem na construção de modelos que expliquem aspectos ou fenômenos da natureza, que possam ser generalizados e sirvam para uma aplicação tecnológica. A imagem ao perder em analogia e ganhar em abstração, admite funções de símbolos, em que são necessárias apropriações de convenções culturais elaboradas para o reconhecimento dos elementos que a compõem.

Algumas pesquisas desenvolvidas no âmbito da Educação em Ciências demonstram dificuldades relacionadas à produção e à recepção das imagens presentes em materiais didáticos de Física. Ao analisar livros didáticos, Otero, Moreira e Greca (2002) verificaram que sua produção parece assumi-las como evidentes e transparentes, isto é, elas não necessitariam de interpretação para sua compreensão. Entretanto, Silva (2006) defende as imagens visuais como objetos simbólicos e, como tais, "produzidos histórico-socialmente como parte da cultura humana" (p.72). Nas imagens com alto grau de abstração, por não serem apresentadas as formas como os modelos são construídos, estas parecem transparentes, como se fossem a própria realidade e não sua representação relacionada a conceitos e ideias. Isso "dificulta e distorce a compreensão sobre a própria natureza do conhecimento científico" (Medeiros; Medeiros, 2001 apud Silva, 2006). Jiménez Valladares e PeralesPalacios (2002) examinam exemplos de imagens presentes em livros didáticos de Física e Química cuja utilização como argumento visual paraconvencer os leitores dos conceitos expostos se apresenta de forma abusiva, ambígua ou errônea, tendo um efeito prejudicial ou nulo no aprendizado.

1 Schollhammer, Karl Erik. Além do visível: o olhar da literatura. Rio de Janeiro: 7Letras, 2007. 
Do estudo realizado por Souza, Rego e Gouvêa ${ }^{1}$, em consulta feita em 74 periódicos publicados entre 1998 e 2007, foram encontrados 13 artigos que abordavam a imagem no ensino de Física, e, destes, 9 pesquisavam a imagem no livro didático e 5 estavam relacionados ao uso da imagem no Ensino Superior.

Os que examinavam a imagem em livros didáticos destinados ao Ensino Superior somaram 4 artigos, dos quais 2 também se referiam ao seu uso no Ensino Médio. Três se situavam no campo de estudos da cognição e 1 no da didática. Um dos artigos (Aguilar; Maturano, 2007) utiliza imagens retiradas de livros didáticos para investigar concepções alternativas de estudantes dos cursos de Licenciatura em Astronomia e Geofísica acerca do movimento de projéteis próximos à superfície da Terra. Otero, Moreira e Greca (2002) analisaram como as imagens são usadas em 41 livros de Física (10 universitários) de acordo com categorias originadas do exame dos livros. Peduzzi (1999) apresenta um conjunto de imagens retiradas, a maioria, da Internet e empregadas na complementação de um texto de Mecânica, tendo em vista seu potencial para o aprendizado.

O único artigo (dos 13 mencionados anteriormente) que apresenta os professores como sujeitos da pesquisa, investiga quais são suas ideias acerca das imagens utilizadas em materiais educativos (livros didáticos, vídeos, softwares, Internet). Seus resultados apontam que "a problemática das imagens na educação em ciências, teria que ser incorporada tanto na formação dos futuros professores como na capacitação daqueles que se encontram em serviço" (Fanaro; Otero; Greca, 2005, p. 5-6, tradução nossa).

Tendo em vista a revisão bibliográfica realizada sobre o tema imagem, admitimos a necessidade de uma alfabetização para sua leitura, principalmente da imagem utilizada no ensino de Ciências.

O objetivo do presente artigo é expor o resultado da análise das imagens presentes em material didático impresso utilizado na disciplina Introdução às Ciências Físicas 1 (ICF1), ministrada no primeiro período da modalidade semipresencial do curso de Licenciatura em Física da Universidade Federal do Rio de Janeiro (UFRJ). Para isso, examinamos as formas de produção das imagens, os elementos que as compõem e seu nível de iconicidade.

\section{Produção e Recepção de Imagens}

O processo de produção das imagens visuais passou por algumas modificações, desde as imagens registradas em rochas e pedras, aos desenhos em papel, pinturas em telas, fotografias,

1 Souza, Lucia Helena Pralon; REGO, Sheila Cristina Ribeiro; GOUVÊA, Guaracira. A imagem em artigos publicados no período 1998-2007 na área de Educação m Ciências (no prelo). 
cinema, televisão, vídeo, até as desenvolvidas por meio de linguagem computacional. Hoje, convivemos com imagens fixas e em movimento, criadas, armazenadas, reproduzidas e transmitidas por meio de diversos suportes. Toda forma de produção da imagem carrega uma maneira de recepção da mesma, ambas marcadas pela tecnologia utilizada que distinguem o agirdo homem no mundo. Dubois (1999) discute algumas características das formas de representação da realidade na pintura, fotografia, cinema, televisão-vídeo e imagens informáticas, tendo em vista três questões: o maquinismo/humanismo, a semelhança/dessemelhança e a materialidade/imaterialidade. Essas características são resumidas no Quadro 1.

A primeira diz respeito ao papel da máquina na relação entre o real representado na imagem e o sujeito. Na pintura, a máquina (por exemplo, a câmera escura) é utilizada para auxiliar a visão do sujeito que produzirá a imagem em um suporte, deixando nele aspectos de sua personalidade, de seu traço, de sua ação, não podendo ser reproduzidos de forma idêntica, pois fazem parte de um tempo e de um espaço já delimitados. O instrumento, assim, é empregado para captar o real. O papel da máquina será modificado com a fotografia: ela não se limita a captar, mas também registra a imagem em materiais fotossensíveis. A função do fotógrafo passa a ser o da escolha do que será registrado, mostrando o que era importante para ele naquele momento, qual sua visão de mundo.

Quadro 1: "Tecnologias" de produção e recepção de imagens

\begin{tabular}{|l|l|l|l|}
\hline \multicolumn{1}{|c|}{ “Tecnologia” } & \multicolumn{1}{|c|}{$\begin{array}{c}\text { Maquinismo/ } \\
\text { humanismo }\end{array}$} & \multicolumn{1}{|c|}{$\begin{array}{c}\text { Semelhança/ } \\
\text { Dessemelhança }\end{array}$} & \multicolumn{1}{|c|}{$\begin{array}{c}\text { Materialidade/ } \\
\text { imaterialidade }\end{array}$} \\
\hline $\begin{array}{l}\text { Pintura (desenho, } \\
\text { escultura) }\end{array}$ & Captação do real & Realismo subjetivo & Imagem sensível \\
\hline Fotografia & Inscrição do real & Realismo objetivo & Imagem afinada \\
\hline Cinema & Visualização do real & Realismo do tempo & Imagem impalpável \\
\hline Televisão (vídeo) & Transmissão do real & $\begin{array}{l}\text { Realismo da } \\
\text { simultaneidade }\end{array}$ & Imagem eletrônica \\
\hline Imagem informática & Concepção do real & $\begin{array}{l}\text { Simulação da } \\
\text { semelhança }\end{array}$ & Imagem virtual \\
\hline
\end{tabular}

A recepção da imagem sofre uma transformação com o cinema, uma vez que são inseridas máquinas de projeção, sem as quais a visualização da imagem em movimento se tornaria impossível. Com as telas de pintura, os desenhos no papel, as esculturas e as fotografias podemos 
"possuir a imagem" e sem a necessidade de um intermediário para sua visualização. Já o cinema não nos permite "tocar a imagem".

A televisão vem modificar a relação entre máquina e sujeito no que concerne à transmissão da imagem. Pessoas geograficamente afastadas podem observar, simultaneamente, os mesmos acontecimentos, em tempo real.

Na imagem informática, a máquina transforma a concepção do real; ela dá origem ao real por meio de programas computacionais. O real não precisa mais ser reproduzido, ele pode ser produzido, no sentido de que a presença do objeto ou de um acontecimento a ser registrado não é indispensável para a confecção da imagem.

Os níveis de iconicidade da imagem, isto é, sua analogia com a realidade representada, são abordados por Dubois (1999) na questão da semelhança/dessemelhança. A marca do artista na pintura carrega sua subjetividade, sua interpretação da realidade (realismo subjetivo). O peso dessa interpretação parece diminuir com a fotografia, uma vez que não é mais a mão do fotógrafo que inscreve a imagem. Embora possa se pensar que a fotografia ganhe em objetividade (realismo objetivo), o fotógrafo se faz valer de técnicas que orientam o observador à leitura esperada por ele (Barthes, 1990).

O cinema vai além do realismo espacial, trazendo o realismo do tempo por meio da reprodução do movimento. Como a imagem é gravada, esse movimento pode ser repetido, revisto, invertido; é um tempo passado, que existiu e que podemos ver transcorrer. A imagem em tempo real transmitida pela televisão aproxima ainda mais o observador da realidade: é observada, senão no espaço em que ela é originada, no instante e no desenvolvimento de sua criação.

Mesmo com a possibilidade de dar origem a figuras nunca vistas, a imagem informática, geralmente, tenta imitar a realidade, criando figuras mais próximas do que já é conhecido, simulando o que se pode visualizar.

Na pintura, a materialidade da imagem é sensível: pode-se sentir o cheiro, o brilho, o relevo, a textura, o "corpo da imagem". Em relação à pintura, a fotografia apresenta uma imagem mais afinada (Dubois, 1999); há uma perda de relevo, de textura, a ação das substâncias que possibilitam a inscrição da imagem no negativo é da mesma natureza, produzindo, ainda assim, imagens diferentes.

Apesar da presença material da imagem fixa no fotograma que dá existência às imagem em movimento do cinema, sua projeção torna a imagem final imaterial. Projetada numa tela, ela não pode ser tocada. Se a tela for deslocada ou manchada, a imagem continuará a mesma. A representação do movimento é produzida na mente do observador através da exposição de seus 
olhos a 24 imagens fixas por segundo. O movimento não está registrado em uma representação material, ele é produzido mentalmente.

O sinal que transmite as informações que se transformam em imagens televisivas é uma impulsão elétrica, sem realidade material. Diferente do cinema, que ainda tem o fotograma (ou filme-película) em que as imagens fixas podem ser tocadas, o sinal que gera a imagem na televisão é formado "por três entidades: os sinais cromáticos, luminosos e de sincronização. Em todo caso, esse sinal nunca é visível como imagem (Dubois, 1999, p.81).

Na informática, mais uma vez, a imaterialidade da imagem, expressa por sua criação pode meio de algoritmos, traz a busca pela aproximação da materialidade através, por exemplo, de "telas táteis", "capacetes de visão" e "luvas de dados" que buscam dar a sensação de imagem "palpável". Ao ser incorporada nas fotografias e filmes, a imagem digital modifica a materialidade da imagem do cinema e da fotografia: não há mais a necessidade de registro da imagem num material fotossensível uma vez que a mesma é armazenada num dispositivo que a lê a transmite em linguagem computacional.

Conforme o homem desenvolve novas tecnologias, há uma tendência em tentar fazer uso delas em atividades de ensino. Nas últimas décadas, com a evolução das técnicas de impressão e reprodução, as representações visuais se tornaram efetivamente presentes nos livros didáticos. Atualmente, aproximadamente, $50 \%$ da superfície dos livros didáticos da educação básica são dedicados às ilustrações (Jiménez Valladares; Perales Palacios, 2001), mostrando a necessidade e/ou importância atribuída à imagem no processo educacional.

\section{Análise do material didático}

O material da disciplina ICF I (Almeida, 2006; Almeida, 2004; Campos, 2008) foi escolhido por ser ministrado no primeiro período do curso da Licenciatura em Física, sendo, assim, o primeiro contato dos estudantes com o conteúdo escolar trabalhado no nível superior. Essa disciplina, juntamente com Introdução às Ciências Físicas 2 (ICF2), tem como objetivos trabalhar de forma mais profunda conceitos científicos apresentados no ensino médio e introduzir os estudantes na realização de atividades didáticas de laboratório. Atualmente, ela abrange os conteúdos de Ótica (Módulo 1), Mecânica (Módulo 2) e Astronomia (Módulo 3).

A Ótica é utilizada para a ilustração da elaboração de um modelo científico sem a necessidade de ferramentas da matemática que não tenham sido desenvolvidas na educação básica. Os conceitos fundamentais da Física são estudados na Mecânica. A inserção da Astronomia ajuda os futuros professores a compreenderem noções principais presentes no cotidiano referentes à observação do céu, como as fases da Lua, as marés e as estações do ano. 
O material didático, além de ser fundamental para o acesso ao conteúdo e o auxílio em sua compreensão, no curso semipresencial também tem a finalidade de promover a interação entre estudantes e professor: é a forma como o professor "chega" ao estudante. Essa interação se dá por meio de material impresso, audiovisual e virtual.

Realizamos a análise das imagens que fazem parte da apresentação conceitual do conteúdo, pois as relacionadas aos exercícios e atividades experimentais têm objetivos diferentes das primeiras, necessitando de um exame particular. Imagens que possuíam mais de um elemento em sua constituição foram consideradas como uma única imagem por conterem a mesma legenda, ou, quando esta não existia, por estarem próximas e fazerem parte de uma determinada discussão conceitual. Aquelas imagens pertencentes a uma sequência, como as das histórias em quadrinhos, foram analisadas separadamente ao terem legendas diferentes.

Foram analisadas 91 imagens no Módulo 1, 154 no Módulo 2 e 90 no Módulo 3. Aquelas que continham algum tipo de erro, seja no corpo do texto que faz referência a ela, na legenda ou dentro da própria imagem, não fizeram parte da análise. Apesar de Moles (1976) considerar como imagens toda forma de representação do real, atribuindo um nível de iconicidade a cada uma delas, não foram consideradas como imagens tabelas construídas pelos autores, equações e fórmulas não acompanhados por ilustrações.

\section{Produção das imagens}

Sendo a produção o momento de construção da mensagem imagética, ela se refere às diferentes "tecnologias" utilizadas em sua criação (Dubois, 1999). Encontramos imagens produzidas através do desenho, fotografia e pintura (Gráfico 1). Por desenho entendemos todas as imagens que pudessem ser originadas da ação manual sobre o papel, mesmo que elas tenham sido desenvolvidas com suporte informático.

Verificamos a presença preponderante dos desenhos, seguidos das fotografias e das pinturas. As duas únicas pinturas encontradas foram as que apresentavam os retratos de Galileu e Newton (Módulo 3). No Módulo 2, encontram-se fotografias de ambientes celestes (Lua, Terra, estrelas), de construções e de uma bússola. 


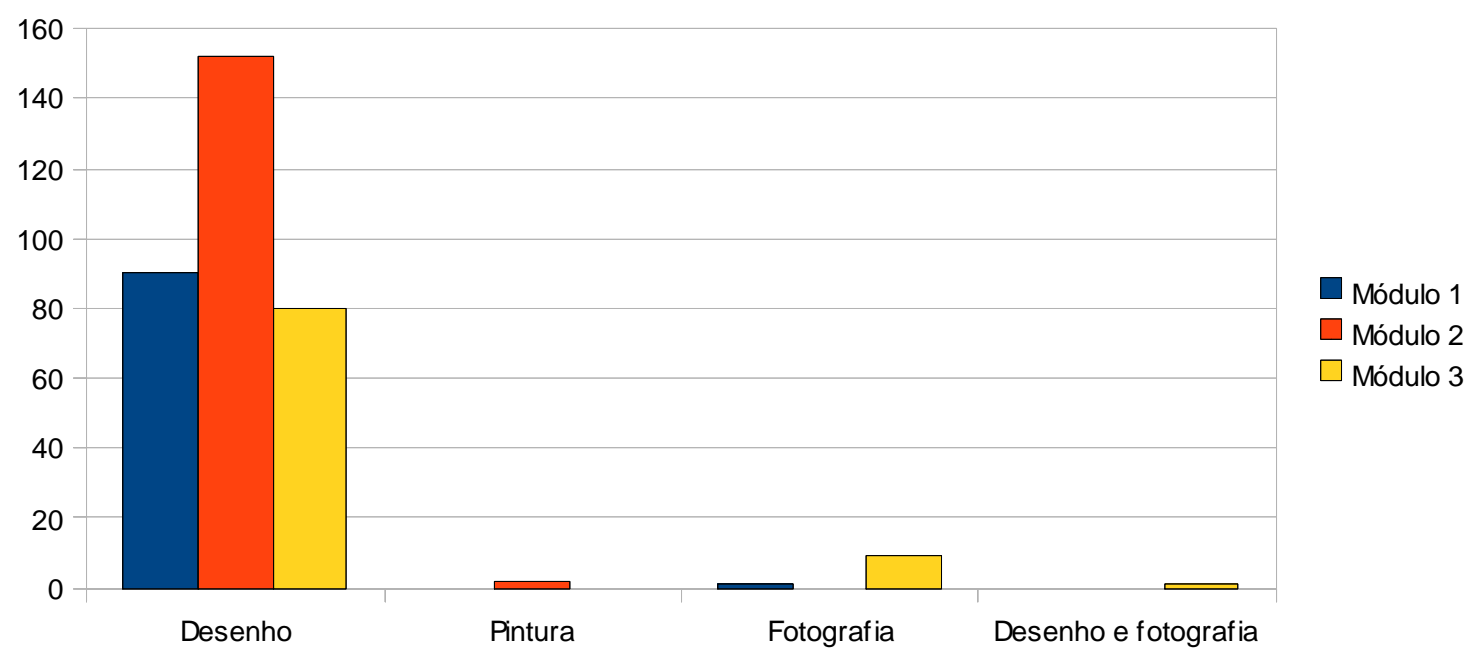

Figura 1: Formas de produção das imagens

\section{Composição das imagens}

Esta categoria se relaciona aos elementos que compõem as imagens analisadas, isto é, o que as imagens apresentam ao leitor (artefatos, homem, partes do corpo humano, esquemas de Física etc). As imagens foram classificadas de acordo com a distribuição apresentada no Quadro 2, onde acrescentamos os tipos E6, H e I do quadro construído por Gouvêa e Oliveira (2010). Algumas observações devem ser feitas a respeito da análise das imagens de acordo com asclassificações desse quadro:

1. Como artefatos foram considerados todos os tipos de objetos produzidos culturalmente.

2. Como cotidiano entende-se lazer ou atividade doméstica.

3. Como atividades de produção e serviço entende-se àquelas referentes ao mundo do trabalho.

4. Elementos da natureza englobam todos os seres vivos, em parte ou inteiros, e minerais.

5. Consideramos elementos do mundo natural e cultural aqueles que dão conta dos equipamentos, máquinas, seres vivos etc.

Os esquemas de Física estão presentes em quase $80 \%$ (110) das imagens do Módulo 2, referentes aos componentes E1 (0,6\%), E2 (0,6\%), E3 (4\%), E4 (4\%), E5 (2\%), E6 (22\%) e H (38\%). No módulo 3, apesar de numa frequência menor, os esquemas de Física continuam preponderantes, fazendo parte de $61 \%$ das imagens (54), onde observamos uma quantidade maior dos componentes E6 (51\%). No Módulo 1, apenas 6 (7\%) imagens não possuem esquemas de Física. 
Quadro 2: Composição da imagem

\section{A - Artefatos}

Tipo 1: aqueles específicos de atividades em laboratório. (A1)

Tipo 2: aqueles relacionados às atividades de produção e serviço. (A2)

Tipo 3: objetos do cotidiano. (A3)

\section{B - Artefatos + Homem}

Tipo 1: homem com artefato específico de atividades de laboratório. (B1)

Tipo 2: homem com artefato específico de atividades de produção e serviço. (B2)

Tipo 3: homem com objetos do cotidiano. (B3)

\section{C - Artefatos + parte do corpo humano}

Tipo 1: parte humana em experimento. (C1)

Tipo 2: parte humana com artefato do tipo A2. (C2)

Tipo 3: parte humana com artefato do tipo A3. (C3)

\section{D - Elementos com intervenção técnica}

Tipo 1: Imagens do mundo natural e cultural ou do homem em atividade (laboratório ou serviço) que passaram por tratamento pictórico para evidenciar aspectos que não podem ser visíveis sem tal procedimento. (D1)

\section{E - Elementos do mundo natural e cultural + esquemas da física}

Tipo 1: Artefatos do tipo A1 e esquemas da física. (E1)

Tipo 2: Artefatos do tipo A2 e esquemas da física (E2)

Tipo 3: Artefatos do tipo A3 e esquemas da física (E3)

Tipo 4: Elementos da natureza e esquemas da física (E4)

Tipo 5: Elementos da natureza, artefatos e esquemas da física (E5) 
Tipo 6: Elementos da natureza, artefatos com intervenção técnica e esquemas da física (E6)

\section{F - Tirinhas/desenhos}

Tipo 1: Tirinhas de personagens e de autoria, adotadas para ilustrar partes do conteúdo. (F1)

Tipo 2: Tirinhas construídas especialmente para ilustrar o conteúdo. (F2)

\section{G - Imagens Ilustrativas}

Tipo 1: Imagens que não estão na cadeia argumentativa de uma demonstração conceitual e não ilustram experimento. (G)

\section{H - Esquemas da Física}

Tipo 1: Como esquemas da física, entendem-se os sinais, fórmulas e indicações de algum objeto, fenômeno e processo que são traduzidos em linguagem matemática ou símbolos. $(\mathrm{H})$

\section{I-Elementos da natureza}

Tipo 1: Apenas elementos do mundo natural (I) 


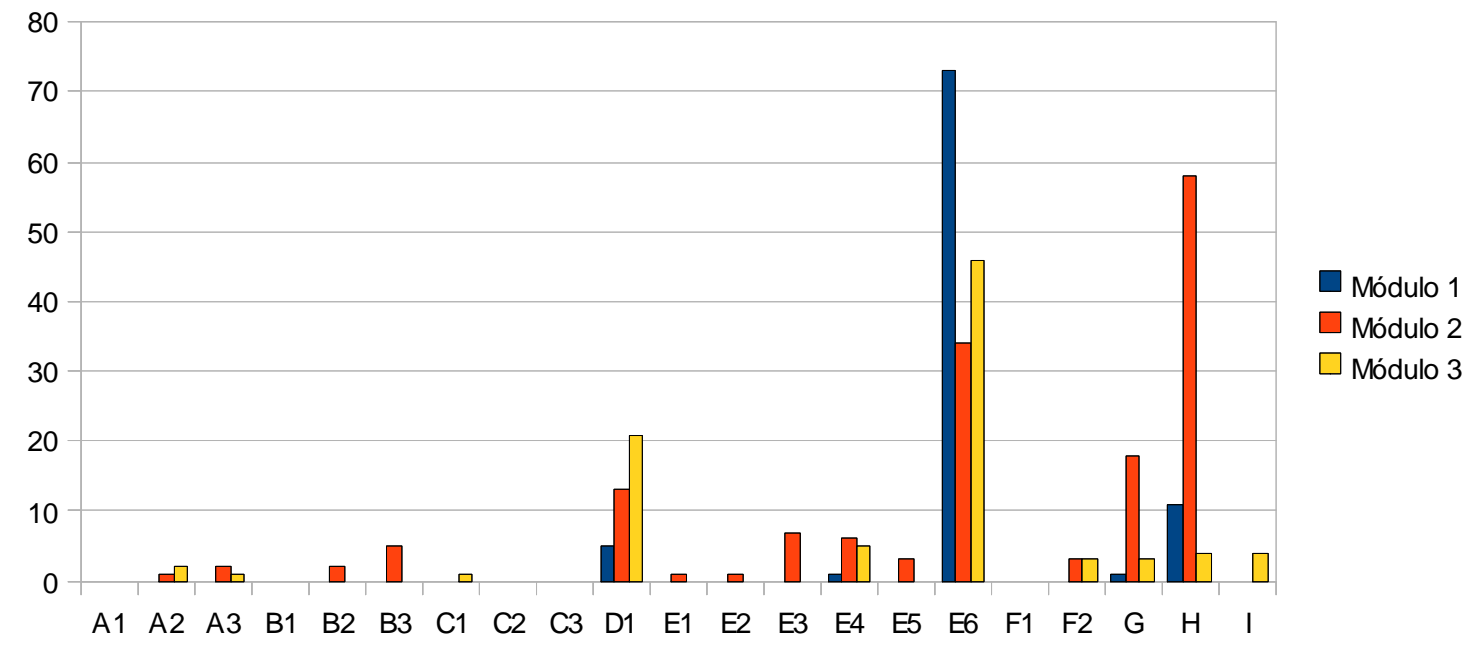

Figura 2: Composição das imagens

\section{Iconicidade das imagens}

Aparici, García Matilla e Valdivia Santiago (1992) apresentam, como uma das características básicas da imagem, o seu nível de iconicidade (propriedades comuns à imagem e ao objeto representado) em contraponto com seu nível de abstração (a imagem deixa de parecer com o objeto, mas não perde sua significação). À medida que a imagem diminui seu nível de iconicidade, ela ganha em abstração, ou seja, ela se torna convencional. 
A

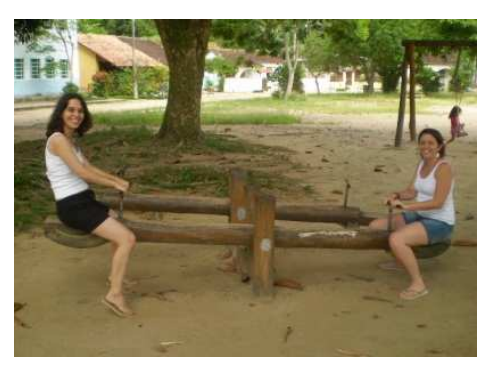

B

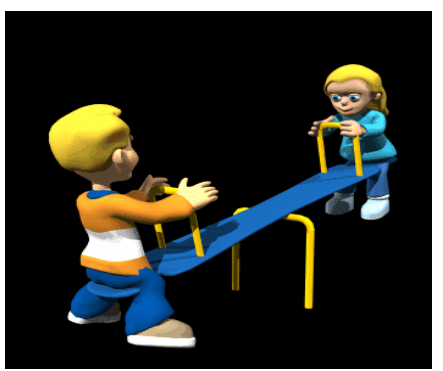

C

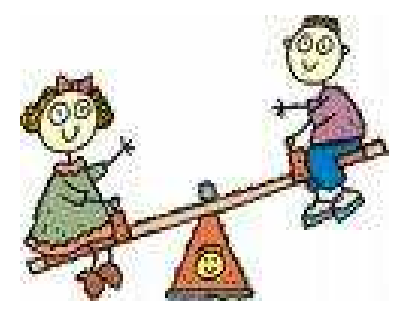

D

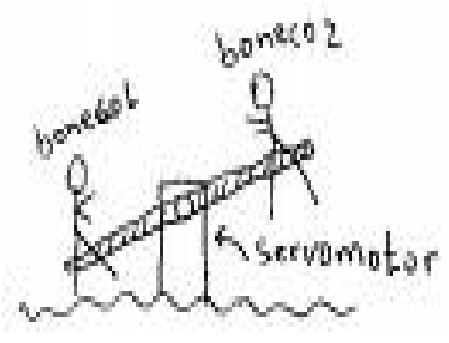

$\mathrm{E}$

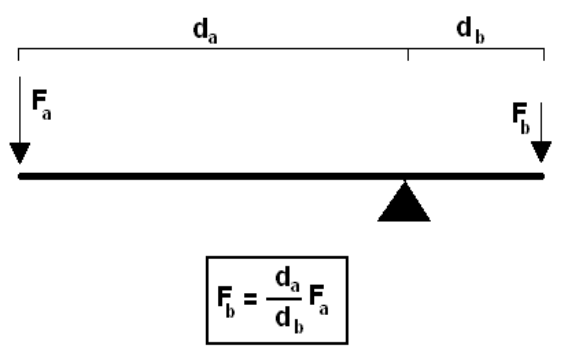

Figura 3: Níveis de iconicidade decrescente

(Fonte: A) arquivo pessoal;

B) http://www.josiasdesouza.folha.blog.uol.com.br/arch2007;

C) http://www.mudapalmeiras.com.br/site/Imgs/gangorra.gif;

D) http://www.grandeideiaestudio.com.br/multimidia/proj;

E)http://www.commons.wikimedia.org/wiki/File:Alavanca.GIF)

Moles (1976), citado pelos referidos autores, criou uma escala de 13 níveis de iconicidade decrescente (Quadro 3), em que a imagem de iconicidade máxima (e, consequentemente, de abstração mínima) é o próprio objeto, passando pelas construções bi e tridimensionais, de tamanho reduzido ou aumentado (por exemplo, o globo terrestre), fotografia, desenho, até, por último, a linguagem verbal (textos) e fórmulas algébricas que apresentam abstração máxima (iconicidade mínima). A figura 4 contém cinco imagens apresentadas em ordem decrescente de níveis de iconicidade. 
Em nosso estudo, quando uma imagem era constituída por elementos de diferentes níveis de iconicidade (por exemplo, um desenho acompanhado de uma fotografia), classificamos a imagem no menor nível, porque entendemos que para compreendê-la totalmente, o leitor necessita ser capaz de decodificar mensagens em níveis maiores de abstração.

Quadro 3: Iconicidade x abstração das imagens

(Fonte: Souza, Lucia Helena Pralonde. Imagens científicas e ensino de ciências:uma experiência docente de construção de representações simbólicas a partir do referente real. In: ENCONTRO NACIONAL DE DIDÁTICA E PRÁTICA DE ENSINO, 15. Anais do XV ENDIPE - Encontro

Nacional de Didática e Prática de Ensino. Belo Horizonte: UFMG,2010. 1 CD-ROM)

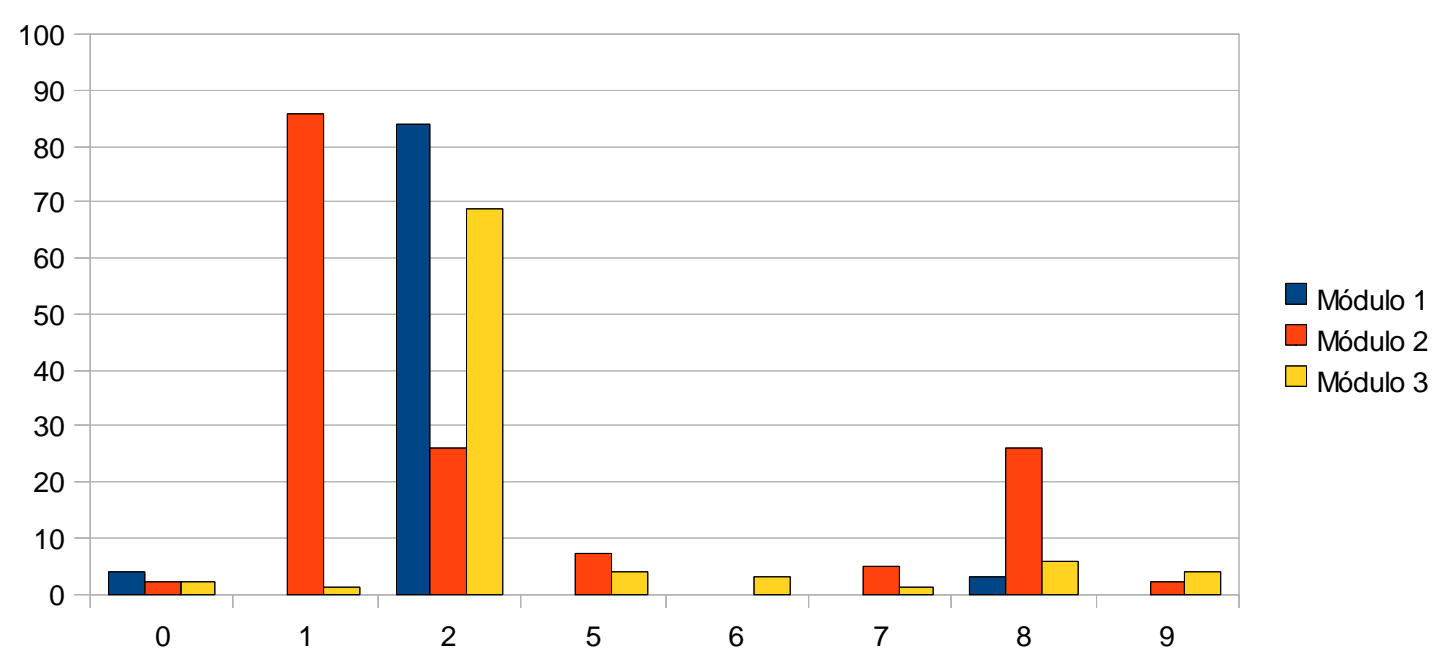

Figura 4: Iconicidade das imagens

\begin{tabular}{|c|c|c|c|c|}
\hline \multicolumn{2}{|c|}{ Iconcidade } & Definição & Critério & Exemplos \\
\hline 12 & 0 & $\begin{array}{l}\text { Objeto em si } \\
\text { mesmo }\end{array}$ & $\begin{array}{l}\text { Objeto e imagem } \\
\text { coincidem mas existe uma } \\
\text { relação de representação, } \\
\text { quer dizer, o objeto está } \\
\text { colocado em um estado } \\
\text { 'comunicativo'. }\end{array}$ & Objeto na vitrine \\
\hline 11 & 1 & $\begin{array}{l}\text { Modelo bi ou tri } \\
\text { dimensional em } \\
\text { escala }\end{array}$ & $\begin{array}{l}\text { O modelo possui todas ou } \\
\text { grande parte das } \\
\text { propriedades sensíveis do } \\
\text { objeto, como cor e forma, }\end{array}$ & Maquetes, esculturas \\
\hline
\end{tabular}




\begin{tabular}{|c|c|c|c|c|}
\hline & & & $\begin{array}{l}\text { mas que podem ser sido } \\
\text { modificadas arbitrariamente. }\end{array}$ & \\
\hline 10 & 2 & $\begin{array}{l}\text { Esquema bi ou } \\
\text { tri dimensional } \\
\text { reduzido ou } \\
\text { aumentado. }\end{array}$ & $\begin{array}{l}\text { Cores e materiais escolhidos } \\
\text { segundo critérios lógicos. }\end{array}$ & $\begin{array}{l}\text { Mapas ridimensionais, } \\
\text { globo terrestre, cartas } \\
\text { geológicas. }\end{array}$ \\
\hline 9 & 3 & $\begin{array}{l}\text { Fotografias ou } \\
\text { projeções } \\
\text { realistas sobre } \\
\text { um plano. }\end{array}$ & $\begin{array}{l}\text { Com relação analógica ponto } \\
\text { a ponto, entre a realidade e } \\
\text { sua projeção. A imagem } \\
\text { apresenta um grau de } \\
\text { definição equiparado ao } \\
\text { poder resolutivo do olho. }\end{array}$ & $\begin{array}{l}\text { Fotografias, cartazes, } \\
\text { catálogos ilustrados. }\end{array}$ \\
\hline 8 & 4 & $\begin{array}{l}\text { Desenhos ou } \\
\text { fotos de } \\
\text { contorno. Perfis. }\end{array}$ & $\begin{array}{l}\text { A imagem mantém uma } \\
\text { relação correta com a } \\
\text { realidade através de critérios } \\
\text { de similaridade, contorno de } \\
\text { formas, silhueta. }\end{array}$ & Caricaturas, silhuetas. \\
\hline 7 & 5 & $\begin{array}{l}\text { Esquema } \\
\text { anatômico ou de } \\
\text { construção. }\end{array}$ & $\begin{array}{l}\text { A imagem se simplifica e pode } \\
\text { mostrar coisas que não se vê } \\
\text { a primeira vista. Se } \\
\text { representa o que se vê e o } \\
\text { que se sabe. }\end{array}$ & $\begin{array}{l}\text { Corte anatômico. } \\
\text { Corte de um motor } \\
\text { mostrando seus } \\
\text { componentes } \\
\text { internos. }\end{array}$ \\
\hline 6 & 6 & $\begin{array}{l}\text { Imagem } \\
\text { fragmentada. }\end{array}$ & $\begin{array}{l}\text { A imagem se apresenta em } \\
\text { uma disposição artificial e } \\
\text { suas partes se organizam em } \\
\text { uma disposição perspectiva } \\
\text { de peças segundo suas } \\
\text { relações espaciais. }\end{array}$ & $\begin{array}{l}\text { Gibi, seqüência, } \\
\text { mosaico. }\end{array}$ \\
\hline 5 & 7 & $\begin{array}{l}\text { Esquema de } \\
\text { princípios } \\
\text { (eletricidade e } \\
\text { eletrônica) }\end{array}$ & $\begin{array}{l}\text { Todas as características } \\
\text { sensíveis foram abstraídas, } \\
\text { exceto a forma, a qual pode } \\
\text { ter sido estilizada ou } \\
\text { geometrizada. A imagem é } \\
\text { um símbolo reconhecido }\end{array}$ & $\begin{array}{l}\text { Planta baixa de casa } \\
\text { ou área. }\end{array}$ \\
\hline
\end{tabular}




\begin{tabular}{|c|c|c|c|c|}
\hline & & & $\begin{array}{l}\text { (pictograma). Interessa mais } \\
\text { conhecer e comunicar do que } \\
\text { assemelhar à realidade. }\end{array}$ & \\
\hline 4 & 8 & $\begin{array}{l}\text { Organograma ou } \\
\text { esquema. }\end{array}$ & $\begin{array}{l}\text { Desaparecem todas as } \\
\text { características sensíveis e os } \\
\text { elementos são quadros } \\
\text { reunidos por conexões } \\
\text { lógicas, hierárquicas. }\end{array}$ & $\begin{array}{l}\text { Organograma de } \\
\text { empresa, de sítios da } \\
\text { web. }\end{array}$ \\
\hline 3 & 9 & $\begin{array}{l}\text { Esquema de } \\
\text { formulação. }\end{array}$ & $\begin{array}{l}\text { Relações lógicas e } \\
\text { topológicas, em um espaço } \\
\text { não geométrico, entre } \\
\text { elementos abstratos. As } \\
\text { relações são simbólicas, todos } \\
\text { os elementos são visíveis. }\end{array}$ & $\begin{array}{l}\text { Mapas mentais, } \\
\text { sociogramase } \\
\text { fórmulas químicas. }\end{array}$ \\
\hline 2 & 10 & $\begin{array}{l}\text { Esquemas em } \\
\text { espaços } \\
\text { complexos. }\end{array}$ & $\begin{array}{l}\text { Combinação em um mesmo } \\
\text { espaço de representação de } \\
\text { elementos esquemáticos } \\
\text { abstratos (flechas, retas, } \\
\text { plano, objeto), pertencentes a } \\
\text { sistemas diferentes. }\end{array}$ & Diagramas de forças \\
\hline 1 & 11 & $\begin{array}{l}\text { Esquema de um } \\
\text { espaço } \\
\text { puramente } \\
\text { abstrato e } \\
\text { esquema } \\
\text { vetorial. }\end{array}$ & $\begin{array}{l}\text { Todas as propriedades foram } \\
\text { abstraídas à dimensões } \\
\text { vetoriais com magnitudes } \\
\text { (quantidade, direção, sentido) } \\
\text { susceptíveis de serem } \\
\text { representadas em um ponto. }\end{array}$ & Gráficos vetoriais \\
\hline 0 & 12 & $\begin{array}{l}\text { Descrição em } \\
\text { palavras } \\
\text { normalizadas ou } \\
\text { em fórmulas } \\
\text { algébricas }\end{array}$ & $\begin{array}{l}\text { A imagem consiste em signos } \\
\text { puramente abstratos sem } \\
\text { conexão imaginável com o } \\
\text { significado ou com a } \\
\text { realidade. }\end{array}$ & $\begin{array}{l}\text { Palavras, textos, } \\
\text { números, contas. }\end{array}$ \\
\hline
\end{tabular}

Numa primeira análise, verificamos que quase todas as imagens (90\% no Módulo 1, 90\% no Módulo 2 e 79\% no Módulo 3) possuíam alguma mensagem linguística em seu interior, sejam palavras, números, relações algébricas e letras nomeando eixos coordenados, indicando pontos a serem considerados ou designando grandezas vetoriais. Isso agruparia a maioria das imagens no 
nível de iconicidade0. Sendo assim, achamos mais proveitoso para o exame das imagens, desconsiderar qualquer texto que as acompanhavam.

Através da Figura 5, observamos o predomínio dos níveis de iconicidade1 e 2, correspondentes a 92\% das imagens do Módulo 1 (iconicidade 2), 73\% do Módulo 2 (iconicidades 1 e 2) e 78\% do Módulo 3 (iconicidades 1 e 2). As de menores níveis de abstração (níveis 8 e 9) abarcam apenas 3\% das imagens do Módulo 1, 2\% do Módulo 2 e 11\% do Módulo 3.

\section{Considerações}

O exame do material confirma o uso que se faz no ensino de Física de imagens com algo grau de abstração para o entendimento de conceitos científicos. Por nossa experiência como professoras de Física, já esperávamos encontrar uma forte influência de imagens com funções simbólicas, isto é, cujo "significado de seus elementos só pode ser entendido com a ajuda do código de uma convenção cultural" (Santaella e Nöth, 2008, p.150), código esse compartilhado por determinados grupos.

Ainda que o avanço tecnológico nos permita a digitalização e impressão de imagens, não encontramos no material analisado imagens provenientes de simulações computacionais, ou de programas de televisão, vídeo e cinema. Além disso, houve uma frequência baixa de fotografias, sendo a maioria das imagens originadas de desenhos. O desenho (assim como a pintura e a escultura) como é impregnado pela interpretação da realidade do seu autor, é influenciado pelos contatos que ele estabelece com o mundo social, neste caso, a comunidade científica, haja visto a quantidade de esquemas de Física presentes nas imagens.

Por estarmos analisando conteúdos de Ótica e Mecânica, encontramos a utilização dos elementos da geometria, dos esquemas vetoriais e relações entre grandezas expostas em forma de gráficos, todos construídos socialmente para a representação de conceitos científicos com pouca ou nenhuma relação de semelhança com a realidade representada.

Uma análise mais minuciosa das imagens poderia nos informar se o material explora a passagem de representações mais icônicas para as mais abstratas ou vice-e-versa (como mostrada na Figura 4), o que talvez ajude na aquisição, por parte dos estudantes, do código necessário à leitura das imagens, com os quais podem não estar habituados a trabalhar. Pela baixa frequência das fotografias no material analisado, à primeira vista, parece que essa passagem não é feita. Entretanto, para confirmar essa suposição precisaríamos examinar isoladamente os elementos presentes na categoria "desenho" segundo sua analogia com a realidade.

Ainda assim, os elementos que compõem as imagens analisadas, por mais icônicos que pudessem ser, geralmente, apresentam-se acompanhados de esquemas da Física. Isso parece 
indicar que não há uma preocupação de inserir esses esquemas após uma exploração de aumento gradual no nível de abstração das representações. Mas, como as imagens foram contadas de acordo com suas legendas, seria necessário observar se elas são construídas em forma de sequência, como a apresentada na Figura 4. Essa figura se fosse analisada segundo nossos critérios, seria classificada como, desenho (forma de produção), E6 (elementos da imagem) e nível de iconicidade1, por apresentar vetores (não consideramos os textos e expressões algébricas à nossa análise).

Apesar das limitações do estudo, o exame do material sugere a necessidade de uma alfabetização para a leitura de imagens utilizadas no ensino de Física, referente à apropriação dos códigos culturais requeridos para a compreensão dos conceitos científicos. O fato do material analisado ser destinado à formação de futuros professores torna essa alfabetização ainda mais importante, pois se trata de prepará-los para trabalhar com a linguagem científica expressa em imagens nos níveis de ensino fundamental e médio, o que talvez, possibilitaria uma melhor compreensão dos conceitos físicos, tão temidos e não entendidos por grande parte dos estudantes.

\section{Referências}

Aguilar, Susana; Maturano, Carla; Núnez, Graciela. Utilizacioón de imágenes para ladetección de concepciones alternativas: unestudioexploratorio com estudiantesuniversitarios. Revista

Electrónica de Enseñanza de lasCiencias, Espanha, v. 6, n. 3, p.691-713, set./out. 2007. Disponível em: <http://www.saum.uvigo.es/reec/>. Acesso em: 14 fev. 2008.

Almeida, Maria Antonieta T. de. Introdução às Ciências Físicas 1, v.1, 3ạ edição. Rio de Janeiro: Fundação CECIERJ, 2006.

. Introdução às Ciências Físicas, v.2. Rio de Janeiro: Fundação CECIERJ, 2004.

Aparici, Roberto; García Matilla, Agustin;Valdivia Santiago, Manuel. La imagen. Madrid:

Universidad Nacional de Educación a Distancia (UNED), 1992.

Bachelard, Gaston. A noção de obstáculo epistemológico - Plano da obra. In: BACHELARD, Gaston.

A formação do espírito científico - Contribuição para uma psicanálise do conhecimento. 6 a

reimpressão. Rio de Janeiro: Contraponto, 2005. p. 17-28.

Barthes, Roland. O óbvio e o obtuso: ensaios críticos III. 3a impressão. Rio de Janeiro: Nova Fronteira, 1990

Campos, Jose Adolfo S. de. Introdução às Ciências Físicas 1, v.3, 4ạ edição. Rio de Janeiro: Fundação CECIERJ, 2008. 
Chalmel, Loic. Imagens de crianças e crianças nas imagens: representações da infância na iconografia pedagógica nos séculos XVII e XVIII. Educação e Sociedade, Campinas v. 25, n. 86, p. 57-74, abr. 2004.

Comenius, Johann A. Orbissensualiumpictusquadrilinguis. Leutschovle: Samuel Brewer, 1685. Costa, Marco Antonio F. da et al. O desenho como estratégia pedagógica no ensino de ciências. Revista Electrónica de Enseñanza de lasCiencias, Espanha, v. 5, n. 1, p.184-191, jan/abr, 2006. Disponível em: <http://www.saum.uvigo.es/reec/>. Acesso em: 14 fev. 2008.

. A construção da biossegurança através de imagens: contribuições para o ensino de ciências. Revista Electrónica de Enseñanza de lasCiencias, Espanha, v. 6, n. 1,p.20-31, jan./abr. 2007. Disponível em: <http://www.saum.uvigo.es/reec/>. Acesso em: 14 fev. 2008.

Dubois, Philippe. A linha geral (as máquinas de imagens). Cadernos de Antropologia e Imagem, Rio de Janeiro, v. 9, n. 2, p. 65-85, 1999.

Fanaro, Maria de losÁngeles; OTERO, Maria Rita; GRECA, lleana María. Lasimágenes em losmateriales educativos: lasideas de losprofesores. Revista Electrónica de Enseñanza de lasCiencias, Espanha, v. 4, n. 2,p.1-6, maio/ago. 2005. Disponível em: <http://www.saum.uvigo.es/reec/>. Acesso em: 14 fev. 2008 Gouvêa, Guaracira; Oliveira, Carmen Irene C de. IMAGENS NO LIVRO DIDÁTICO: elementos de mediação em práticas de ensino. In: ENCONTRO NACIONAL DE DIDÁTICA E PRÁTICA DE ENSINO, 15. Anais do XV ENDIPE - Encontro Nacional de Didática e Prática de Ensino. Belo Horizonte: UFMG,2010. 1 CD-ROM)

Jiménez Valladares, Juan de Dios; Perales Palacios, F. Javier. Aplicacióndelanálisissecuencial al estudiodel texto escrito e ilustraciones de loslibros de física y química de la ESO. Enseñanza de lasCiencias, Barcelona, v. 19, n. 1, p. 3-19, jan./abr. 2001.

- La evidencia experimental a través de laimagen de loslibros de texto de Física y QuímicaRevista Electrónica de Enseñanza de lasCiencias, Espanha, v. 1, n. 2, maio/ago. 2002. Disponível em: <http://www.saum.uvigo.es/reec/>. Acesso em: 14 fev. 2008.

Macedo, Elizabeth. A imagem da ciência: folheando um livro didático. Educação e Sociedade, Campinas, v. 25, n. 86, p.103-129, abr. 2004.

Medeiros, Alexandre; Medeiros, Cleide. Questões epistemológicas nas iconicidades de representações visuais em livros didáticos de Física. Revista Brasileira de Pesquisa em Educação em Ciências, Belo Horizonte, v. 1, n. 1, p. 103-117, jan./abr. 2001.

Moles, Abraham A. Em busca de uma teoria ecológica da imagem? In: Anne-Marie Thibault-Laulan (ed.). Imagem e Comunicação. São Paulo: Melhoramentos, 1976. 
Otero, Maria R.; Moreira, Marco. A.; Greca, lleana M. El uso de imágenes em textos de Física para laenseñanza secundaria y universitaria. Investigações em Ensino de Ciências, Porto Alegre, v. 7, n. 2,p. 127-154, maio/ago. 2002.

Peduzzi, Luiz O. Q. Imagens complementares a um texto de Mecânica: a perspectiva de seu potencial para o aprendizado do aluno. Revista Brasileira de Ensino de Física, São Paulo, v. 21, n 1, p. 136-151, mar. 1999.

Santaella, Lucia; Noth, Winfried. Imagem: cognição, semiótica e mídia. 1ạ edição. São Paulo: Iluminuras, 2008.

Silva, Henrique C. da. Lendo imagens na educação científica: construção e realidade. ProPosições, Campinas, v. 17, n. 1,p.71- 83, jan./abr. 2006.

Teixeira, Luzia M. G.; Compiani, Mauricio; Newerla, Vivia B. Observação e produção de textos a partir de imagens geocientíficas. Revista Ciência e Ensino, Campinas, v. 1, n.1, p. 41-46, 2006.

Sheila Cristina Ribeiro Rego. Docente do Departamento de Disciplinas Básicas da Graduação do Centro Federal de Educação Tecnológica Celso Suckow da Fonseca (CEFET/RJ). Doutoranda em Educação em Ciências e Saúde do Núcleo de Tecnologia Educacional para a Saúde (NUTES) da Universidade Federal do Rio de Janeiro (UFRJ).scrrego@ig.com.br

Guaracira Gouvêa de Sousa. Docente do Departamento de Didática do Centro de Ciências Humanas e Sociais da Universidade Federal do Estado do Rio de Janeiro (UNIRIO) e pesquisadora credenciada da Universidade Federal do Rio de Janeiro (UFRJ). Doutora em Ciências. guaracirag@uol.com.br 